\title{
XXXVIII. On the disappearance of Saturn's ring in the year 1803
}

\section{Professor J.E. Bode}

To cite this article: Professor J.E. Bode (1803) XXXVIII. On the disappearance of Saturn's ring in the year 1803, Philosophical Magazine Series 1, 15:59, 219-222, DOI: $10.1080 / 14786440308676260$

To link to this article: http://dx.doi.org/10.1080/14786440308676260

曲 Published online: 18 May 2009.

Submit your article to this journal

Џ Article views: 2

Q View related articles $\sqsubset$ 


\section{$\left[\begin{array}{lll}219 & 1\end{array}\right.$}

XXXVIIT. On the Difappearance of Saturn's Ring in the Year 1803. By Profelfor J. E. BoDE*.

$\mathrm{T}$ HE plane of Saturn's ring, as is well known, during the whole of his revolution of thirty years round the fun, retains its parallelifm, and interfects the plane of the ecliptic in 17 degrees of Pifces and of Virgo at an angle of $3 \mathbf{I}_{2}^{1}$. The neceffary confequence, therefore, is, that the northern fide of the ring is iltuminated for fifteen years by the oblique rays of the fun, and then the fouthern for the fame period. It muft alfo happen, that in the above places the plane of the ring paffes twice through the fun in each revolution, at which time the edge of the ring only is illuminated. But the edge or thicknefs of the ring being too fmall to admit of its being feen from the earth on account of the great diftance of Saturn, the ring becomes invifible. For fifteen years the earth and the fun are on the fame fide of the ring, which is the illuminated fide, and therefore the ring during that period is always vifible; but a little before, and at that period when the plane of the ring paffes tbrough the fun, or when Saturn's heliocentric place is in $17^{\circ}$ of $\not$ or of my in the afcending or defcending nodes of the ring, the earth and the fun may firft be on one fide and then on the other fide of the ring. In the firft cafe, as long as its plane does not pafs through the fun it will be vifible from the earth; but in the other cafe it will be invifible. The earth, therefore, can then pafs feveral times through the plane of the ring, at which time the ring will appear like a right line, or be entirely invifible; the confequence of which is, that the ring will be aiternately vifible and invifible.

This alternation of difappearing and reappearing will be exbibited by the ring in the year 1803 . The fun, having illuminated the fouth fide of the ring fince October 1789, will pals through the plane of it in the month of June 1803 , and will illuminate the northern fide, when Saturn pafies heliocentrically the afcending node of his ring; and in the mean time the plane of the ring will pafs three times through the earth, which will be firft on the fide illuminated by the fun, and then on the oppofite or darkened fide; in confequence of which the ring feen from the earth will be twice vifible and invifible in the courfe of a few months.

Thefe phrenomena will be better comprehended by infpeeting the annexed figure, which fuppoles the obferver to be

* From his Afronomijeb Fabr Bucb for 1003 . 


\section{Difappearance of Saturn's Ring in the Year 1803.}

placed in Saturn. This figure, then, exhibits the exact inclination of the plane of the ring to the ecliptic; the apparent motion of the earth and the fun, as feen from Saturn, together with the time of the paffage of thefe planets through the afcending node of his ring. (See Plate V. fig. 2.)

$A B$ is the ecliptic feen from Saturn in the fign of Pifces, and divided into degrees. The afcending node of Saturn's ring feen from thence is placed in $17^{\circ} 6^{\prime}$, in which point the plane of the ring interfects the ecliptic at an angle of $3 \mathrm{I}^{\circ} 20^{\prime}$. The eye is then in that plane. Thus the ring appears as a ftraight line; $n n$ is the north fide, and $z z$ the fouth fide of it. The dotted line CD is the folar orbit feen from Saturn ; and the fun's place is marked in it on the firt day of each month, from November 1802 to October 1803 . Thefe places of the fun are directly oppofite to the heliocentric places of Saturn: the longitude thus differs fix figns, and the northern latitude of Saturn feen from thence changes into the fouthern of the fun. In this manner, the fun in November, December, January, and to the month of June, illuminates the fouth fide of the ring; but always in a fainter manner, the nearer he comes to the plane of it. On the $15^{\text {th }}$ of June he paffes through the plane in $e$. The ring at that time is illuminated on the edge, and can be feen only by powcrful telefcopes as a fine luminous line.

The longitude of the point $e$, reduced to the ecliptic, falls in $f$, or $20^{\circ} 42^{\prime}$ of Pifces. The fun, then, about the middle of June begins to illuminate the northern fide of the ring; in July, Anguit, September, October, \&c. he recedes more and more from the plane of the ring, and the illumination of it then becomes ftronger.

The elliptical line is the earth's orbit as feen from Saturn, according to its direct and retrograde motion from the ift of November 1802 to the Ift of Ostober 1803 , and its place is marked on the firft of each month. Its longitude is fix figns lefs or more than the geocentric longitude of Saturn; and the northern latitude of Saturn is changed into the fouthern of the earth.

Now, as the figure clearly hows, the earth in November and December 1802 is reprefented on the fouth fide, or turned towards the fun, and therefore on the illuminated fide of the ring. But afterwards the, earth approaches more and more to the plane of the ring; and, as the ring receives the folar rays in a more and more oblique manner, the ring not only becomes narrower but even decreafes in light. On the $13^{\text {th }}$ of Decomber, as may be feen by this fmall figure, the earth cnters the plane of the ring, and paffes to the 
Philo.Alag Pl.V.Tol.XV.

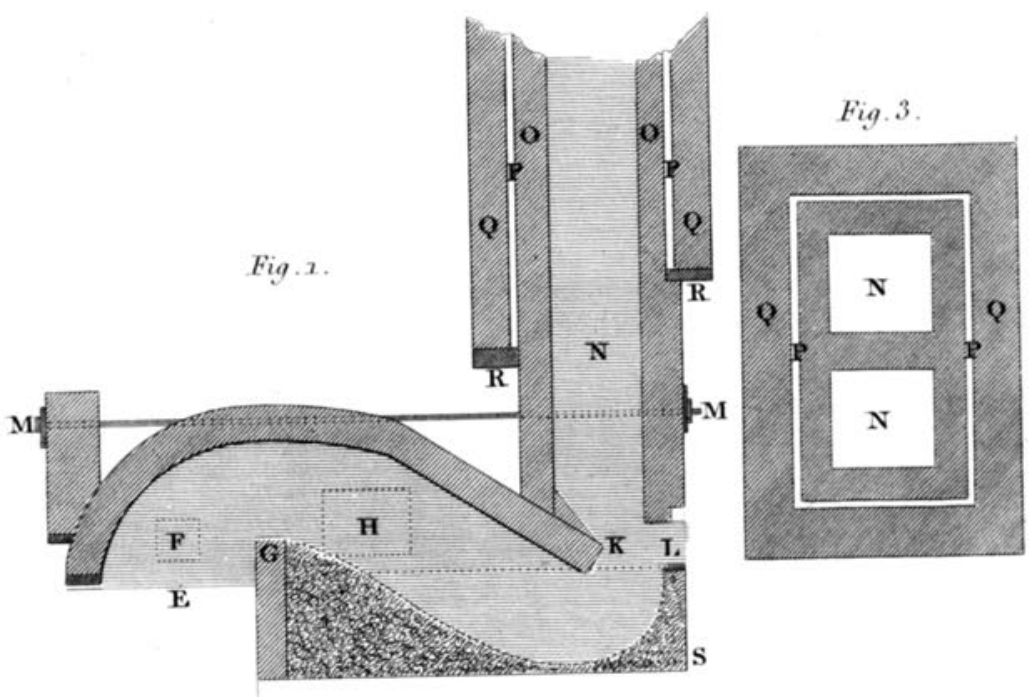

Fig.e.

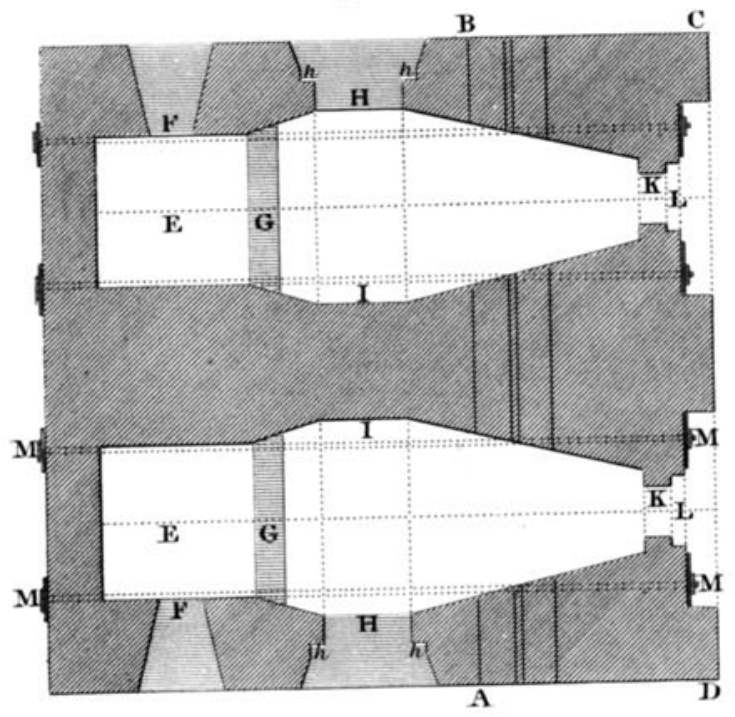


northern fide of it, which is turned from the fun. The ring then, for the firft time, becomes to us invifible: but this invilibility is not of long continuance; for, as may be feen by the figure, the earth on the Ift of January, by its Saturniocentric apparent retrograde motion, paffes a fecond time through the plane of the ring, and goes to the fouthern or illuminated fide, and the ring then begins to appear again as a ftraight line. In February, March, and April, the earth recedes more and more from the plane, and the ring becomes broader and more perceptible. But the fun during thefe months approaches nearer to the plane of the ring, and by thefe means it is illuminated in a more oblique direction. In the month of May the earth is at its greateft diftance from the plane of the ring, while the fun approaches it more and more till the middle of June, when he paffes through the plane in $e$, and the ring for the fecond time becomes totally invifible to the earth, which is then on its dark fide. From this period, during the month of July and till Augnit, the ring will remain in this ftate. About the 18 th of Augut the earth will pafs, for the third time, through the plane of the ring, as it will then be on the northern, which is now the illuminated fide of the ring : it will again appear as a traight line, and be vifible when viewed through good telefcopes: it will increafe in light and breadth in September and October in proportion as the earth and the fun recede from the plane.

Between the ift of November 1802 and the Ift of OAtober 3803 the ring of Saturn twice difappears and twice reappears. At the firft difappearance on the $13^{\text {th }}$ of December 1802 , Saturn in the morning will be in the ealtern part of the heavens; and the firft reappearance will be about the 7 th of Jnnuary 1803 ; Saturn in the night-time being on the fame fide of the heavens.

At the fecond difappearance in the middle of June, Saturn in the night will be in the wett, and, as he fets half an bour after midnight, the phrenomenon may be obferved. But at the fecond and laft difippearance in Auguft, Saturn will be after the fun, and therefore the phanomenon cannot be feen. In the month of Oetober, when Saturn emorges from the fun's rays, he may be feen before fun-rife in the ealt, and the ring then will be very vifible.

In regard to the above calculation of the times of the difappearance and reappearance of Saturn's ring, the accuracy of them, and the correfpondence of then with the phanomena, mult depend on the accuracy of the tables and the theory hitherto adopted in regard to the poftion of the ring. 
The ftate of the atmolphere alfo, and the different power of the telefcopes and of the eyes of the obfervers, may occafion fome variation. The difappearance and reappearance of the ring, which are occafioned by the earth paffing through its plane, can be better and more conveniently obferved than thofe which take place in confequence of the paffage of the fun through that plane, becaufe the earth, on account of its quicker motion, paffes fooner through the plane of the ring than the fun.

As the fix firft fatellites of Jupiter move in the fame plane with the ring, when the ring difappears, or becomes like a luminous line, thefe fatellites mult appear on both fides of Saturn in a right hine, and can then be more readily difcovered and diftinguifhed from fixed ftars.

XXXIX. On the Difappearance of the Ring of Saturn. By Van Beick CaLKoen, Profeffor of Aftronomy at Leyden*.

T HE plane of Saturn's ring, according to aftronomical obfervations, has always a direction parallel to itfelf, fo that it interfects the ecliptic in $17^{\circ} 18^{\prime}$ of $m$ and $\not$, at an angle of $31 \frac{1}{2}^{\circ}$, and the orbit of Saturn at $20^{\circ} 42^{\prime}$ of 设 and *. Now, if Saturn as feen from the fun be in longitude $20^{\circ} 42^{\prime}$ of $x$, the plane of the ring will pafs through the centre of the fun; by which the edge of the ring being illuminated, while the nortbern and fouthern furface receive no light, it muft become invifible, and can be feen only by the moft powerful telefcopes as a fine luminous line. On the $\mathbf{1 5}^{\text {th }}$ of June next Saturn will be in this fituation; and as this planet employs about thirty years in its revolution round the fun, this phænomenon takes place only once in 15 years. Other phenomena, however, in confequence of which the ring before the $\mathbf{I}^{\text {th }}$ of June will alternately difappear and reappear, are connected with this flate of the planet. "Thefe phænomena arife from the different pofitions of the earth, which in the courfe of its revolution is at one time above and at another below the plane of the ring; fo that from the 1 it of November 1802 to October 1803 the ring will be twice invifible and twice vifible; firt the fouthern and then the northern, then the fouthern and afterwards the northern furface will be alternately feen from the earth within the courfe of ten months. For determining and caleulating thefe phænomena with more accuracy, Lambert in-

* From Algemeene Konft en Letter-Bode, No. 13, for 1803 . yented 